\title{
Melanopsin, photosensitive ganglion cells, and seasonal affective disorder.
}

\author{
Kathryn A Roecklein \\ Patricia M Wong \\ Megan A Miller \\ Shannon D Donofry \\ Marissa L Kamarck
}

See next page for additional authors

Follow this and additional works at: https://jdc.jefferson.edu/neurologyfp

\section{Let us know how access to this document benefits you}

\author{
Recommended Citation \\ Roecklein, Kathryn A; Wong, Patricia M; Miller, Megan A; Donofry, Shannon D; Kamarck, Marissa \\ $\mathrm{L}$; and Brainard, George C, "Melanopsin, photosensitive ganglion cells, and seasonal affective \\ disorder." (2013). Department of Neurology Faculty Papers. Paper 66. \\ https://jdc.jefferson.edu/neurologyfp/66
}

This Article is brought to you for free and open access by the Jefferson Digital Commons. The Jefferson Digital Commons is a service of Thomas Jefferson University's Center for Teaching and Learning (CTL). The Commons is a showcase for Jefferson books and journals, peer-reviewed scholarly publications, unique historical collections from the University archives, and teaching tools. The Jefferson Digital Commons allows researchers and interested readers anywhere in the world to learn about and keep up to date with Jefferson scholarship. This article has been accepted for inclusion in Department of Neurology Faculty Papers by an authorized administrator of the Jefferson Digital Commons. For more information, please contact: JeffersonDigitalCommons@jefferson.edu. 


\section{Authors}

Kathryn A Roecklein, Patricia M Wong, Megan A Miller, Shannon D Donofry, Marissa L Kamarck, and George C Brainard 
Review

\title{
Melanopsin, photosensitive ganglion cells, and seasonal affective disorder ${ }^{\text {th }}$
}

\author{
Kathryn A. Roecklein ${ }^{\mathrm{a}, *}$, Patricia M. Wong ${ }^{\mathrm{a}}$, Megan A. Miller ${ }^{\mathrm{a}}$, Shannon D. Donofry ${ }^{\mathrm{a}}$, \\ Marissa L. Kamarck ${ }^{\mathrm{a}}$, George C. Brainard ${ }^{\mathrm{b}}$ \\ a Department of Psychology, University of Pittsburgh, 3500 Sennott Square, 210 South Bouquet St., Pittsburgh, PA 15260, USA \\ b Department of Neurology, Thomas Jefferson University, Philadelphia, PA 19107, USA
}

\section{A R T I C L E I N F O}

\section{Article history:}

Received 10 July 2012

Received in revised form 5 November 2012

Accepted 21 December 2012

\section{Keywords:}

Depression

Retinohyopothalamic pathway

Melanopsin

Sleep

Seasonal affective disorder

Photosensitive retinal ganglion cells

\begin{abstract}
A B S T R A C T
In two recent reports, melanopsin gene variations were associated with seasonal affective disorder (SAD), and in changes in the timing of sleep and activity in healthy individuals. New studies have deepened our understanding of the retinohypothalamic tract, which translates environmental light received by the retina into neural signals sent to a set of nonvisual nuclei in the brain that are responsible for functions other than sight including circadian, neuroendocrine and neurobehavioral regulation. Because this pathway mediates seasonal changes in physiology, behavior, and mood, individual variations in the pathway may explain why approximately $1-2 \%$ of the North American population develops mood disorders with a seasonal pattern (i.e., Major Depressive and Bipolar Disorders with a seasonal pattern, also known as seasonal affective disorder/SAD). Components of depression including mood changes, sleep patterns, appetite, and cognitive performance can be affected by the biological and behavioral responses to light. Specifically, variations in the gene sequence for the retinal photopigment, melanopsin, may be responsible for significant increased risk for mood disorders with a seasonal pattern, and may do so by leading to changes in activity and sleep timing in winter. The retinal sensitivity of SAD is hypothesized to be decreased compared to controls, and that further decrements in winter light levels may combine to trigger depression in winter. Here we outline steps for new research to address the possible role of melanopsin in seasonal affective disorder including chromatic pupillometry designed to measure the sensitivity of melanopsin containing retinal ganglion cells.
\end{abstract}

(c) 2013 Elsevier Ltd. All rights reserved.

\section{Contents}

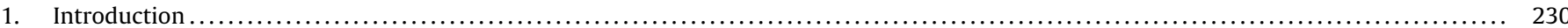

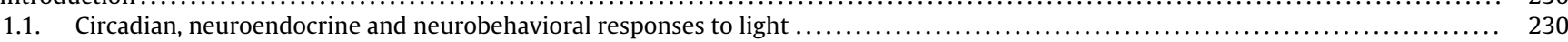

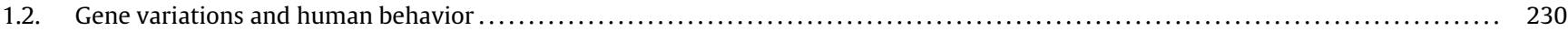

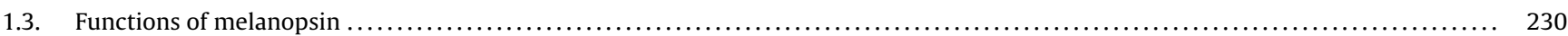

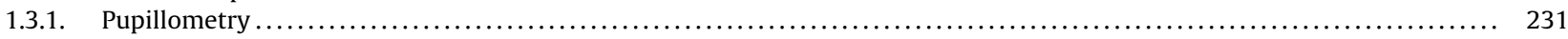

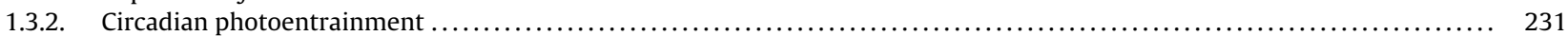

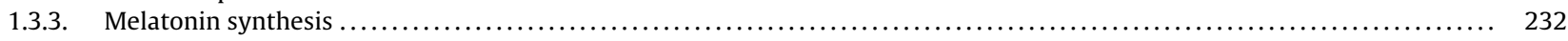

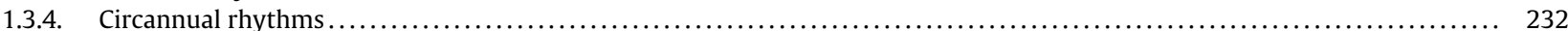

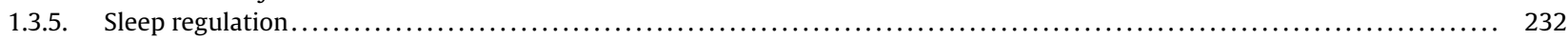

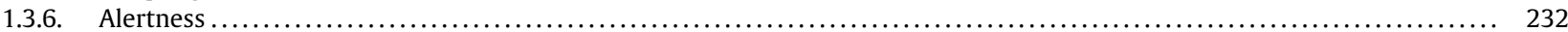

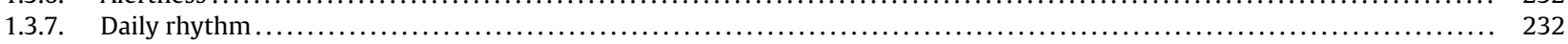

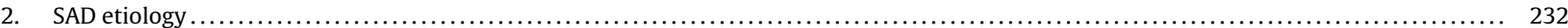

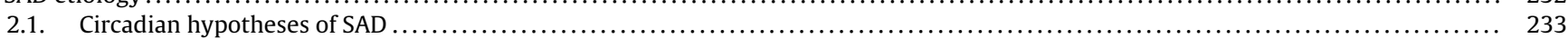

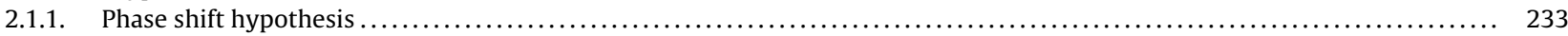

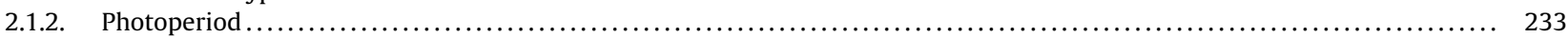

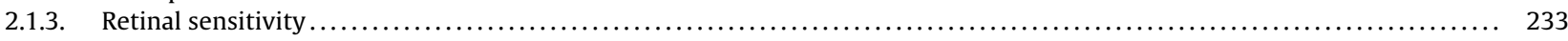

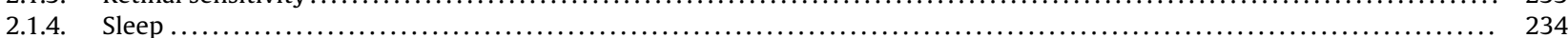

\footnotetext{
论 OMIM ID: 606665

* Corresponding author. Tel.: +1 412624 4553; fax: +1 4126482002.

E-mail addresses: kroeck@pitt.edu, kroecklein@gmail.com (K.A. Roecklein).
} 


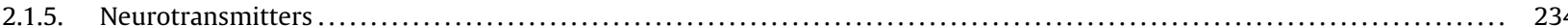

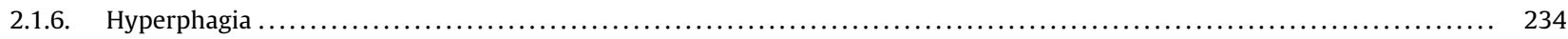

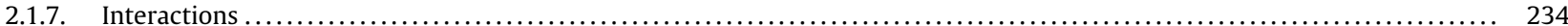

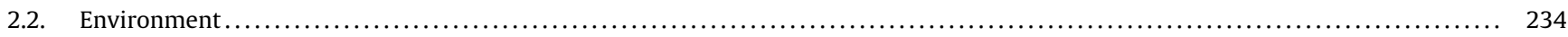

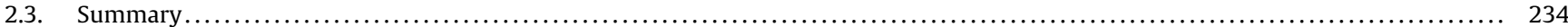

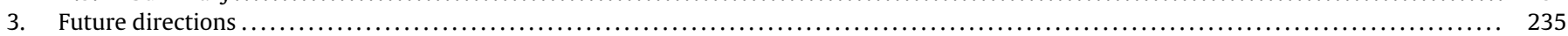

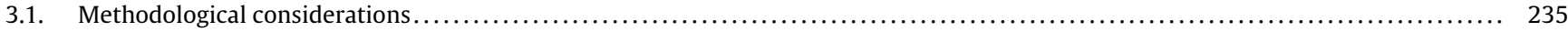

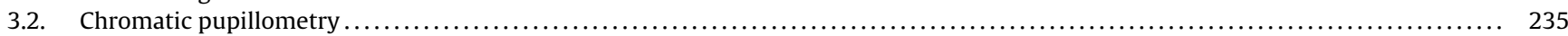

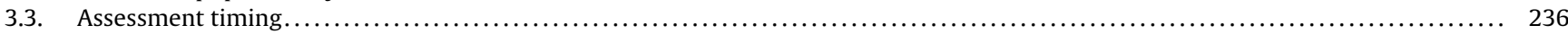

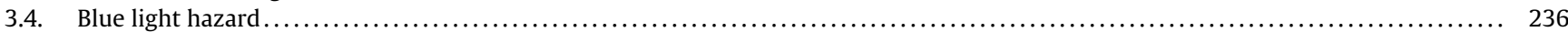

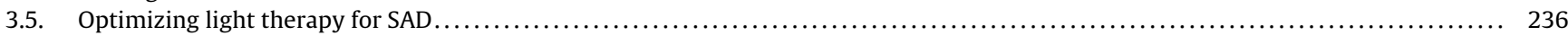

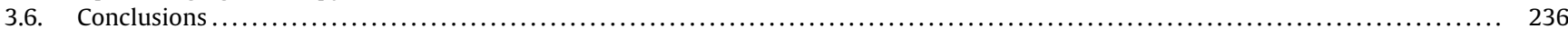

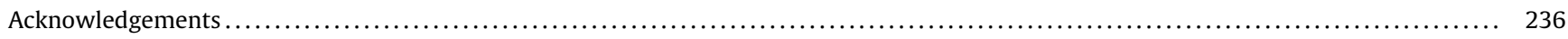

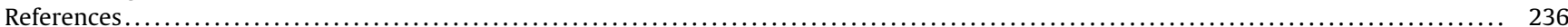

\section{Introduction}

The recently described melanopsin light input pathway may contribute to our understanding of seasonal affective disorder (SAD). SAD involves recurrent depressive episodes in the fall or winter months with remission or a change to mania or hypomania in the spring (Rosenthal et al., 1984). SAD is common and pervasive, affecting $0.8-2.2 \%$ of the North American population (Lam and Levitt, 1999). Three evidence-based treatments exist (i.e., antidepressant medications, light therapy, and psychotherapy), but not all SAD patients respond fully to these treatments. Incorporating research on melanopsin has the potential to improve our understanding of the etiology of SAD by identifying a link between gene variations, biomarkers, and risk for depression, and also to suggest new and individually tailored treatments.

The role of melanopsin in SAD has not been thoroughly explored, although the rationale for further investigation is strong. The regular winter recurrence of episodes, seasonal biological changes, and the benefit of light therapy for SAD suggest that its etiology is rooted in abnormal responses to light. Shorter photoperiods in winter may trigger SAD in susceptible individuals, analogous to other mammalian seasonal responses. An abnormal response to light may be mediated by abnormal retinal signaling (Wehr et al., 2001), termed the retinal subsensitivity hypothesis of SAD (Hebert et al., 2002). Such hypotheses were conceived prior to the description of melanopsin and its role in circadian, neuroendocrine and neurobehavioral processes. Abnormal retinal responses to light could be due to differences in the retinohypothalamic pathway, comprised of retinal ganglion cells that contain the photosensitive protein melanopsin. Some SAD patients differ from controls based on sequence variation in the melanopsin gene (Roecklein et al., 2009). Additionally, those variations are associated with seasonal changes in sleep timing and chronotype (Roecklein et al., 2012). Although melanopsin variations may hypothetically be the physiological basis underlying the retinal subsensitivity hypothesis, other possibilities are discussed as well.

Below, we briefly summarize the neurobiology and function of the melanopsin system, which has recently been reviewed by others (e.g., Do and Yau, 2010). Although the implications of the melanopsin system for human eye disease and human sleep and cognitive performance have been described elsewhere (e.g., Kawasaki and Kardon, 2007), this review focuses on the potential role of melanopsin in SAD and possible treatment implications.

\subsection{Circadian, neuroendocrine and neurobehavioral responses to light}

The discovery of melanopsin confirmed that rods and cones are not the only photoreceptors involved in circadian, neuroendocrine, and neurobehavioral responses to light (Provencio et al., 1998).
Melanopsin is found in intrinsically photosensitive retinal ganglion cells (ipRGCs), which are photosensitive even when input from rods and cones is pharmacologically blocked (Berson et al., 2002; Hattar et al., 2002; Gooley et al., 2001). Although melanopsin is found in only $2 \%$ of ganglion cells, their dendrites form a "photoreceptive net" across the retina (Berson et al., 2002; Hattar et al., 2002; Gooley et al., 2001; Provencio et al., 2002). Additionally, melanopsin cell responses increase with light intensity with a high threshold, and they are slow to initiate and terminate nerve impulses, qualities making them ideal for measuring gross environmental light levels rather than forming crisp images (Berson et al., 2002, 2010; Dacey et al., 2005; Pu, 2000). Melanopsin signaling pathways, as established in animal models, have complex inputs from bipolar, amacrine, rod, and cone cells, and multiple projections (Do and Yau, 2010). If conserved in humans, the retinorecipient areas that may be important in SAD include the suprachiasmatic nucleus (SCN) and intergeniculate leaflet (circadian regulation), the lateral hypothalamus (energy homeostasis), and the ventral subparaventricular zone and preoptic nucleus (sleep promotion and regulation; Graham et al., 2008; Hannibal and Fahrenkrug, 2004; Hattar et al., 2002, 2006).

\subsection{Gene variations and human behavior}

We have reported melanopsin gene (OPN4) associations in two populations. In a study of 220 individuals, those with the TT genotype at P10L (rs2675703) had a 5.6 times increased risk of SAD (Roecklein et al., 2009). This association was retested in a healthy sample to remove the effect of mood disorder symptoms. In 268 healthy individuals, the effects of P10L TT genotype and day length interacted to predict earlier bedtime when individuals were assessed on shorter days, and later bedtime when individuals were assessed on longer days (Roecklein et al., 2012). If replicated, and found in SAD as well, these data may indicate a specific etiological relationship between P10L, changes in sleep timing, and SAD. To date, however, these are the only two SNP-association studies showing a link between melanopsin and SAD in the first study, and between melanopsin and seasonal changes in sleep timing in the second study. Replication, and other studies designed to evaluate the role of melanopsin in SAD are needed. Such studies will greatly benefit from the basic science literature describing the functions of melanopsin and melanopsin containing cells.

\subsection{Functions of melanopsin}

Functions that are controlled by photic stimulation of the melanopsin system include the pupil light reflex, circadian photoentrainment, sleep regulation, acute suppression of plasma melatonin, and acute effects of light on cognitive performance, although the expression of these functions varies between humans 
Table 1

Summary of melanopsin findings in human research.

\begin{tabular}{|c|c|c|c|}
\hline Authors & Year & Participants & Findings \\
\hline Thapan et al. & 2001 & 22 Healthy individuals & 459 nm light maximally suppressed melatonin release \\
\hline Brainard et al. & 2001 & 72 Healthy individuals & $446-477 \mathrm{~nm}$ most effective in suppressing nighttime melatonin release \\
\hline Lockely et al. & 2003 & 16 Healthy individuals & $\begin{array}{l}460 \mathrm{~nm} \text { light more effective than } 555 \mathrm{~nm} \text { for phase shift and melatonin } \\
\text { suppression }\end{array}$ \\
\hline Phipps-Nelson et al. & 2003 & 16 Healthy individuals & $\begin{array}{l}\text { 10,000 lx light (fluorescent) reduces subjective sleepiness and improves } \\
\text { psychomotor performance compared to dim } 1000 \mathrm{~lx} \text { (incandescent) }\end{array}$ \\
\hline Cajochen et al. & 2005 & 10 Healthy men & $\begin{array}{l}460 \mathrm{~nm} \text { light more effective than } 550 \mathrm{~nm} \text { light for melatonin suppression, } \\
\text { alerting response, and responses of body temperature and heart rate }\end{array}$ \\
\hline Zaidi et al. & 2007 & 2 Visually impaired individuals & $\begin{array}{l}480 \mathrm{~nm} \text { peak sensitivity for melatonin suppression, phase shifts, acute increase } \\
\text { in alertness, pupillary constriction, and stimulus detection }\end{array}$ \\
\hline An et al. & 2009 & 12 Healthy individuals & $\begin{array}{l}458 \mathrm{~nm} \text { more effective than } 550 \mathrm{~nm} \text { light for cognitive functioning and arousal } \\
\text { level, } 458 \mathrm{~nm} \text { light produced larger effects at nighttime }\end{array}$ \\
\hline Roecklein et al. & 2009 & 130 SAD 90 healthy controls & rs2675703 (P10L) T/T variation higher in SAD than controls \\
\hline Gamlin et al. & 2007 & 2 Healthy men & $\begin{array}{l}\text { Sustained post-stimulus pupilloconstriction (PIPR) maximally sensitive to } \\
482 \mathrm{~nm}\end{array}$ \\
\hline Brainard et al. & 2008 & 26 Healthy individuals & $460 \mathrm{~nm}$ light optimal for melatonin suppression \\
\hline Mure et al. & 2009 & 12 Healthy individuals & $\begin{array}{l}\text { Sustained pupil constriction and PIPR maximally sensitive to } 460-480 \mathrm{~nm} \text {, } \\
\text { evidence for melanopsin bistability }\end{array}$ \\
\hline Revell et al. & 2010 & 12 Healthy men & $\begin{array}{l}479 \mathrm{~nm} \text { light more effective for melatonin suppression, but cognitive } \\
\text { performance more sensitive to other wavelengths indicating involvement of } \\
\text { multiple photoreceptors }\end{array}$ \\
\hline Kankipati et al. & 2010 & 37 Healthy individuals & PIPR evident in response to $470 \mathrm{~nm}$ but not $623 \mathrm{~nm}$ stimulus \\
\hline Gooley et al. & 2010 & 48 Healthy individuals & $\begin{array}{l}\text { Melatonin suppression tests indicate that melanopsin is primarily responsive } \\
\text { to long duration, high irradiance stimuli }\end{array}$ \\
\hline McDougal and Gamlin & 2010 & 6 Healthy individuals & $\begin{array}{l}\text { Cone photoreceptors adapt over } 30 \mathrm{~s} \text {, and rods do not respond at high } \\
\text { irradiances, such that long-duration high irradiance stimuli induce melanopsin } \\
\text { responses }\end{array}$ \\
\hline Kankipati et al. & 2011 & $\begin{array}{l}16 \text { Glaucoma patients } 19 \\
\text { matched controls }\end{array}$ & $\begin{array}{l}\text { PIPR lower in glaucoma patients compared to matched controls, PIPR decrease } \\
\text { correlates with glaucomatous neuropathy }\end{array}$ \\
\hline Kardon et al. & 2011 & $\begin{array}{l}32 \text { Retinitis pigmentosa (RP) } \\
\text { patients } 43 \text { healthy controls }\end{array}$ & RP patients had a more pronounced PIPR compared to controls \\
\hline Zele et al. & 2011 & 11 Healthy individuals & PIPR maximally evident at CT 15, 2 hr 40 min prior to DLMO \\
\hline Gagne et al. & 2011 & 10 SAD 10 healthy controls & $\begin{array}{l}\text { SAD and controls did not differ in ERG after } 1 \mathrm{~h} \text { red or blue stimulus, ERGs } \\
\text { were lower after blue in both groups }\end{array}$ \\
\hline Gagne and Hebert & 2011 & 12 SAD 11 healthy controls & $\begin{array}{l}\text { ERG decrease after } 10,000 \text { lx } 1 \text {-hour exposure in summer and winter in SAD } \\
\text { but not controls, did not differ by wavelength }\end{array}$ \\
\hline Roecklein et al. & 2012 & 234 Healthy individuals & $\begin{array}{l}\text { rs2675703 (P10L) T/T variation interacts with photoperiod to predict } \\
\text { chronotype and sleep timing }\end{array}$ \\
\hline
\end{tabular}

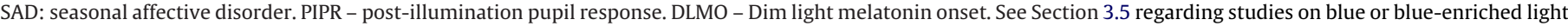
therapy in SAD.

and other mammals. In general, melanopsin knockout mice $\left(O p n 4^{-l-}\right)$ show impairment in many of these measures, indicating that ipRGCs are important for encoding light intensity for animal biological and behavioral responses (Hattar et al., 2003). Some or all of these functions may be relevant to human mood disorders, especially the effects on sleep and cognitive performance. Selected findings from the past decade of human research related to melanopsin phototransduction and physiology are summarized in Table 1.

\subsubsection{Pupillometry}

The contribution of melanopsin to neurobehavioral responses can be distinguished from that of other photoreceptors when exposures to specific wavelengths, intensities, and durations of light are tested. The pupillary light reflex (PLR) adjusts the diameter of the pupil by light intensity, protecting the retina from damage and aiding vision. To date, human studies show that blue but not red wavelengths elicit ongoing constriction during stimulation, ongoing constriction after cessation (i.e., post-illumination pupillary response, PIPR), and that the human PLR driven by melanopsin is most sensitive to short wavelength light but may be potentiated by longer wavelengths (Gamlin et al., 2007; Kankipati et al., 2010; Kawasaki and Kardon, 2007; Mure et al., 2009). Although in rodents, melanopsin contributes about three times more to steady state pupil diameter than cones at high irradiances, rods, cones, and melanopsin cells all contribute to the PLR (Hattar et al., 2003; Lucas et al., 2003; Tsujimura et al., 2010). Although different populations of melanopsin cells exist, the M1 type intrinsically photosensitive retinal ganglion cells (ipRGCs) underlie both circadian photoentrainment and the pupillary light reflex (Schmidt et al., 2011), making it possible to make inferences about the function of one system by measuring the other. Pupillometry in humans is a potential tool for investigating "melanopsin-related disorders" (Gamlin et al., 2007). Extended duration stimuli of specific narrow band wavelengths can be used in a relatively fast and noninvasive way in human studies to isolate the functioning of melanopsin, allowing inferences about the relative sensitivity of melanopsin across diagnostic groups (Do and Yau, 2010; Kardon et al., 2011). Potential clinical applications of pupillometry are broad, from diagnosis of retinal diseases, to possibly discerning the role of melanopsin photoreception in SAD (Kardon et al., 2011; Wilhelm, 2010).

\subsubsection{Circadian photoentrainment}

Although the etiology of SAD has not been determined, one main hypothesis contends that SAD is due to a seasonal circadian phase disturbance, and is discussed more thoroughly below (Lewy et al., 2006). Hence, the role of melanopsin in circadian photoentrainment has implications for this hypotheses of SAD. Data indicate that, in specific conditions of photoentrainment in rodents, about $40-50 \%$ of the response is driven by melanopsin cells (Do and Yau, 2010), although it is unclear if this translates to other nonvisual responses in humans. Melanopsin knockout mice, however, have only subtle changes in their circadian rhythms, indicating that rods and cones convey light information through the melanopsin 
ganglion cells for entrainment. Phase shifts in rhythms of human melatonin in response to $460 \mathrm{~nm}$ light are two-fold greater than those in response to $555 \mathrm{~nm}$ light at high irradiances, indicating a primary role of melanopsin photoreception for human circadian photoentrainment (Lockley et al., 2003).

\subsubsection{Melatonin synthesis}

Melanopsin could also play a role in SAD through the regulation of melatonin. In both humans and animals, the pineal gland releases melatonin at night in response to darkness and signals from the circadian clock (Lewy, 2007; Nelson et al., 2010). Winter nights result in a longer duration of melatonin, which is a biological signal that triggers seasonal behaviors in mammals, such as changes in feeding and sleeping (Schibler, 2007; Workman and Nelson, 2011). Light acts to acutely suppress melatonin, and mice missing rods and cones still exhibit suppression of melatonin (Lucas et al., 1999; Panda et al., 2003), implying that melanopsin is involved in acute melatonin suppression in mice. In humans, short wavelength light between $446-477 \mathrm{~nm}$ is the most effective for acute suppression of melatonin, indicating a primary role for melanopsin in melatonin suppression (Brainard et al., 2001; Revell et al., 2010; Thapan et al., 2001). Cone photoreceptors, in addition, appear to contribute to human melatonin suppression at the beginning of light exposure (Gooley et al., 2010). Both early and late responses to light in humans may be therapeutically important, and optimal light therapy might employ both longer and shorter wavelengths to engage cones as well as melanopsin (Brainard et al., 2001, 2008; Gooley et al., 2010; Revell et al., 2010; Thapan et al., 2001).

\subsubsection{Circannual rhythms}

Many rhythms that recur annually, such as in the seasonally breeding Siberian hamster, are driven by changes in day length and the resulting increase in the duration of nightly melatonin synthesis (see Schibler, 2007 for a review). In addition to melatonin, other circadian markers of season that may also be influenced by melanopsin-mediated light input include photoperiod-dependent patterns of gene expression in rodents (Sumova et al., 2003; Tournier et al., 2003; Travnickova et al., 1996) and seasonal variations in the electrophysiological activity in the rodent central clock that encode day length (VanderLeest et al., 2007). Given the role of melanopsin in melatonin and circadian entrainment described above, seasonal rhythms driven by circadian rhythms or photoperiod would be similarly dependent on individual differences in melanopsin functioning. In healthy humans, controlled laboratory studies have shown that the melatonin rhythm as well as prolactin, cortisol, body temperature and sleep are influenced by photoperiod length (Wehr, 1991; Wehr et al., 1993). Those studies illustrated the conservation of photoperiodic responsiveness of humans, although it has been suggested that in industrialized societies, photoperiodic responses may be masked by higher ambient artificial light levels Wehr et al., 1993). In contrast, one study found no seasonal change in the nightly duration of melatonin release in controls, suggesting that only some subgroups of individuals, notably those with SAD, retained the lengthened duration of melatonin release seen in other mammals (Wehr et al., 2001).

\subsubsection{Sleep regulation}

Since hypersomnia is a primary SAD symptom, the role of melanopsin in sleep regulation may be important. Extensive human research has established that light has clear effects on (1) circadian entrainment of sleep, (2) homeostatic sleep regulation, and (3) acute light-induced effects on alertness. Animal research indicates that melanopsin plays a role in some or all of this sleep regulation and physiology. Melanopsin cells project to neural regions involved in sleep regulation (Hattar et al., 2006) including the ventral lateral pre-optic area (VLPO; Hannibal and Fahrenkrug, 2004;
Lu et al., 2000), and the superior colliculus (SC), which has been implicated in the photic regulation of sleep (Gooley et al., 2003; Miller et al., 1998). In nocturnal rodents, light during the dark activity phase will acutely induce sleep, but in diurnal animals and humans, short wavelength light has the expected opposite effect of increased alertness. Knockouts, however, have significantly reduced acute light-induced activation of the VLPO and SC, and do not exhibit acute sleep responses to light, or experience a delay in such responses (Altimus et al., 2008; Do and Yau, 2010; Lupi et al., 2008; Tsai et al., 2009). Melanopsin appears to be involved in the physiological basis of the homeostatic sleep drive, since melanopsin knockout mice exhibit reduced sleep duration and debt (Tsai et al., 2009).

\subsubsection{Alertness}

Decrements in alertness are also relevant for depression, although light has the opposite effect on nocturnal mice as in diurnal humans. In mice, darkness is alerting during the light phase, but this effect is delayed in melanopsin knockouts, indicating that melanopsin participates in driving acute alertness responses (Altimus et al., 2008; Tsai et al., 2009). These data lead to the hypothesis that a melanopsin-mediated effect on alertness may explain the role of melanopsin in SAD (Schmidt et al., 2011). Human studies have found that light causes an acute increase in cognitive performance and alertness (e.g., Badia et al., 1991; French et al., 1990), especially short wavelength light (An et al., 2009; Cajochen et al., 2005; Lockley et al., 2006; Phipps-Nelson et al., 2003; Revell et al., 2010; Zaidi et al., 2007; Figueiro et al., 2007). Based on spectral sensitivity, however, self-reported alertness ratings are driven by a combination of photoreceptors whose contributions may vary across the day (An et al., 2009; Revell et al., 2010). Although light may increase alertness by suppressing melatonin when it is released, other as yet unidentified process stimulating the ascending arousal system and cortex are likely during the day when melatonin is low (Lockley and Gooley, 2006).

\subsubsection{Daily rhythm}

Daily variations in melanopsin cell numbers, protein, and mRNA have been observed in animals (Gonzalez-Menendez et al., 2009; Hannibal et al., 2005; Sakamoto et al., 2004), although daily variations in melanopsin-related functions may also be due to downstream processes in the melanopsin and circadian pathways. In humans, it appears that a daily variation in the sensitivity of the melanopsin pathway occurs, as reflected by the PIPR (Zele et al., 2011), and melatonin suppression and iris constriction (Figueiro et al., 2005). Objective measures of human cognitive function in response to light are highest at night, after dusk (An et al., 2009). The mechanism behind such daily variation is likely to be due to an interaction between multiple photoreceptors, the clock, and light input (Dacey et al., 2005; Wong et al., 2007). For example, the peak period of melanopsin mRNA expression in rats increases in duration under long day length conditions and is illumination dependent (Mathes et al., 2007). It is possible that a light sensitive transcription feedback loop controls melanopsin activity (Hannibal et al., 2005), such that the effect of light on circadian, neuroendocrine and neurobehavioral processes varies by time of day. Consistent timing of measurement is therefore critical when studying behavioral responses dependent on melanopsin.

\section{SAD etiology}

Although biological hypotheses of SAD have been reviewed elsewhere (Lamont et al., 2007; Levitan, 2007; Rohan et al., 2009), none have yet incorporated the recent findings regarding these melanopsin-containing ganglion cells that regulate the biological and behavioral responses to light. Seasonal changes in circadian 
rhythms and light responses in humans and animals can be healthy or adaptive, but individuals with SAD may experience a pathological extreme of normal human seasonal variation (Magnusson, 2000). In seasonally breeding rodents, multiple biological rhythms vary across the seasons, and such rodents may have utility as potential animal models for SAD (Workman and Nelson, 2011). There is evidence of seasonal variation in humans such as seasonal peaks in birth rates, growth rate, cortisol, testosterone, pain thresholds, alertness, sexual activity and conception, and behaviors such as crime, suicide, all cause mortality, and rape (see Roenneberg and Aschoff, 1990; Lam and Miron, 1991; Workman and Nelson, 2011). Aschoff (1981) suggests that sociocultural factors and increasing industrialization may explain a decrease in amplitude of these seasonal rhythms since the 1930 s. The general U.S. population reports a winter worsening of mood, increased appetite, longer sleep duration, and decreased energy and social interaction levels in winter (Rosen et al., 1990). SAD is seen as the extreme case on a continuum of seasonal variations in mood and behavior (Kasper et al., 1989). In fact, some degree of seasonal depression may have once been adaptive as a means to save energy in winter, although wintertime decrements in activity would be less adaptive in our current environment (Eagles, 2004). Here we describe etiological hypotheses of $\mathrm{SAD}$, with a focus on the possible role of melanopsin in many of the hypotheses.

\subsection{Circadian hypotheses of $S A D$}

\subsubsection{Phase shift hypothesis}

The phase shift hypothesis proposes that SAD occurs when circadian rhythms are out of phase, shifted earlier or later, relative to the sleep/wake cycle (Lewy, 2007). This hypothesis has been defined as the difference between a marker of circadian phase (i.e., DLMO) and mid-sleep, or a misalignment in the phase angle between the circadian clock and the sleep/wake cycle. Although a majority (71\%) of SAD patients have delayed rhythyms (Lewy et al., 2006), approximately half do not have significantly different rhythms compared to controls (46\%; Eastman et al., 1993). This indicates that circadian misalignment alone may not explain SAD etiology. Morning light therapy (or combined morning/evening light) appears superior to evening or midday light therapy administration (Terman et al., 1989). When circadian misalignment is measured, treatment to correct misalignment is associated with decreased depression symptoms in SAD (Lewy, 2007), and the degree of change in misalignment is associated with degree of improvement (e.g., Lewy et al., 2006). It may be that subgroups of individuals with SAD have different directions and degrees of misalignment, perhaps due to different genetic predispositions. Given the role of melanopsin in circadian entrainment, and this evidence for circadian misalignment in SAD, it is not surprising that melanopsin gene variations are associated with changes in sleep timing and chronotype (Roecklein et al., 2012), although these findings have not yet been replicated.

\subsubsection{Photoperiod}

The photoperiod hypothesis of SAD states that longer duration of nocturnal melatonin release, due to longer nights in winter, may be a "circadian signal of change in season," triggering depression (Wehr et al., 2001). Wehr et al. (2001) tested the photoperiod hypothesis in SAD and healthy controls living in their usual environment. Individuals with SAD had longer winter melatonin release (30-48 min in men and women compared to themselves in summer), a seasonal variation not seen in healthy controls (Wehr et al., 2001). Individuals with SAD did not have a significant phase shift compared to healthy controls in winter, but time of melatonin offset and midpoint was consistent with the phase shift hypothesis (Wehr et al., 2001). It remains to be seen if regular light therapy during winter can lead to shortened duration of melatonin release in
SAD, or if gene variations are associated with melatonin. In healthy individuals, there can be large individual differences in nighttime acute suppression of melatonin by light (Brainard et al., 1988). Further, evening melatonin suppression by light is more effective in winter (Owen and Arendt, 1992). Although the factors explaining these seasonal and individual differences in light suppression of melatonin are unknown, one possible explanation could be genetically mediated differences in retinal sensitivity.

\subsubsection{Retinal sensitivity}

The retinal subsensitivity hypothesis proposes that normal increases in retinal sensitivity in response to low light levels in winter is impaired, leading the retina to be less sensitive than necessary (Hebert et al., 2002; Reme et al., 1990). Whole retina recording measures include electroocculography (EOG), and electroretinography (ERG), under either scotopic conditions, reflecting primarily rod responses, or photopic conditions, reflecting largely cone driven responses.

2.1.3.1. Electroocculography. Two studies found lower EOG ratios in SAD, which would reflect lower electrical potential and activity if outside of the normal range (Lam et al., 1991; Ozaki et al., 1993). The first study to analyze season found that healthy individuals had higher EOG ratios in winter compared to summer, a difference not seen in SAD patients (Ozaki et al., 1995). This indicates that the upregulation thought to be required for low winter light levels was not occurring in SAD, and that the lack of up-regulation could be pathological in SAD. In SAD patients responding to one week of winter light therapy, however, low EOG ratios did not rise to the levels seen in controls (Ozaki et al., 1993). The underlying mechanism behind EOG levels is still unclear, making conclusions difficult to draw from this type of recording.

2.1.3.2. Electroretinography. One study using scotopic ERG in response to dim white light flashes found that women with SAD had lower ERG, but men with SAD had higher ERG amplitude compared to controls, while other studies did not find this gender difference (Lam et al., 1992). Both individuals with subsyndromal seasonal affective disorder (S-SAD) (Hebert et al., 2002) and SAD (Hebert et al., 2004) had lower rod sensitivity (i.e., scotopic ERG) in winter compared to controls. This difference normalized in summer and after treatment with light therapy (Hebert et al., 2004). The photopic ERG may also be decreased in SAD in winter, and does not differ from controls after light therapy or in summer (Lavoie et al., 2009). Recently, SAD and control participants were exposed to $10,000,100$, and 5 lx light for one hour (Gagne and Hebert, 2011). A significant decrease in ERG following 10,000 lx $1 \mathrm{~h}$ exposures was found in both summer and winter in SAD but not controls, and is proposed as a biomarker of SAD, although the response was not specific to wavelength. In a recent study using different wavelengths, ERGs were compared between SAD and control participants after either a red or blue $1 \mathrm{~h}$ exposure (Gagne et al., 2011). ERGs were significantly lower after the blue stimuli, but SAD and controls did not differ. There may be other measures, such as chromatic pupillometry (e.g., the PIPR, which is primarily driven by melanopsin containing cells and not rods and cones), that are more sensitive to melanopsin cell functioning than ERG, given that melanopsin cells are only $1-2 \%$ of the ganglion cells in the retina (Provencio et al., 1998) and would contribute less to whole retina recording responses like ERG. Considering synaptic connections through bipolar cells from both rods and cones to the M1 (melanopsin type 1) cells involved in the pupillary light reflex and circadian photoentrainment (Schmidt et al., 2011), it stands to reason that deficits in the classical photoreceptors would impact melanopsin-mediated functions as well. 


\subsubsection{Sleep}

Most individuals with SAD (80\%) report hypersomnia (Kaplan and Harvey, 2009). Despite reports of hypersomnia, studies have not been able to identify changes in sleep architecture and sleep regulation specific to SAD. Although some studies find no differences in homeostatic drive, some evidence suggests a deficiency in the homeostatic drive in SAD (Cajochen et al., 2000). Reports of hypersomnia may also reflect a desire for more sleep as a result of disrupted sleep (Kaplan and Harvey, 2009). When measured actigraphically, individuals with SAD had decreased sleep efficiency, daytime inactivity, greater time in bed, and a phasedelay compared to healthy controls, but showed no increase in actual time spent asleep (Winkler et al., 2005). Home actigraphy and/or polysomnography may help distinguish increased time in bed from increased total sleep time in those reporting hypersomnia (Kaplan and Harvey, 2009). Another important aspect of sleep in SAD may be the timing of sleep, and resultant effects on circadian phase. In healthy individuals, sleep durations of $9 \mathrm{~h}$ and later morning wake times ( $3 \mathrm{~h}$ later) led to a significant phase delay in the timing of dim light melatonin onset (Burgess and Eastman, 2006). When healthy individuals in the same study slept $6 \mathrm{~h}$ and woke at their regular workday time, a phase advance was observed, indicating the importance of morning wake time and light exposure for circadian entrainment. Perhaps individuals with SAD are most similar to those in the $9 \mathrm{~h}$ sleep condition, and are phase delayed as a result, suggesting an interaction between circadian entrainment and sleep.

\subsubsection{Neurotransmitters}

The role of neurotransmitters including serotonin and dopamine (DA) has been investigated in SAD. Variations in DA related genes, such as the $\mathrm{D} 4$ receptor gene variation (DRD4 VNTR), are associated with SAD, specifically with eating behavior, carbohydrate craving, and body mass index (Levitan et al., 2004, 2006). Because DA is additionally involved in modulating retinal sensitivity and neurobiological responses to light, it is possible that SAD etiology could be explained by variations in dopaminergic signaling (Levitan, 2007), independently of melanopsin phototransduction. Future studies may investigate an association between reduced ERG in SAD, as described above, and the DRD4 variation in SAD (Levitan, 2007). More complex interactions between DA, melanopsin, and retinal sensitivity are possible given that DA is involved in light and dark adaptation in the retina (Levitan, 2007; Witkovsky, 2004), melatonin can inhibit DA release, and DA can inhibit melatonin production in the retina (Cahill and Besharse, 1991). DA agonists in the retina cause increased melanopsin mRNA expression (Sakamoto et al., 2005), suggesting the possibility that DA variations may impact melanopsin signaling through regulation of OPN4 mRNA expression. DA also may modulate ipRGC signaling (Van Hook et al., 2012), and ipRGCs appear to project to dopaminergic intraneurons in the retina, thereby contributing to visual signaling (Zhang et al., 2012). Hypodopaminergic states in the retina could change DA mediated signaling in cones (Witkovsky, 2004), and given the contribution of cone signaling to melanopsin containing ganglion cells (Schmidt et al., 2011), it is theoretically possible that DA gene variations could impact melanopsin cell functioning through cone-driven processing. Although disruptions in serotonergic neurotransmission are likely to represent an underlying vulnerability in SAD (e.g., Neumeister et al., 2001), it is less likely that serotonin would interact with melanopsin signaling or retinal sensitivity. The neurotransmitter hypothesis of SAD has been well described elsewhere (Neumeister et al., 2001).

\subsubsection{Hyperphagia}

Individuals with SAD are more likely to report increased appetite, food intake (i.e., hyperphagia), weight gain, and carbohydrate craving. Further, 17-26\% of those diagnosed with SAD present with a comorbid eating disorder diagnosis, particularly Bulimia Nervosa (BN) (Lam et al., 2001). Interestingly, in women with comorbid SAD and BN, light therapy led to a decrease in binge/purge episode frequency, but was more effective in alleviating mood symptoms (Lam et al., 2001). Although light therapy may improve mood, which in turn decreases eating symptomology, it is also possible that increased light levels directly affect eating behavior through modulation of hypothalamic pathways involved in metabolic and energy homeostasis or via circadian physiology. Neuroanatomical studies have demonstrated that melanopsin cells project to the lateral hypothalamus, a region involved in regulating energy homeostasis, suggesting that light may have direct effects on eating and/or metabolism (Hattar et al., 2003).

\subsubsection{Interactions}

Individual differences in light sensitivity could be a function of retinal sensitivity, the sensitivity of the circadian clock to light, reduced light input, or a combination of these factors. Circadian variations in the sensitivity of melanopsin signaling are likely to reflect a complex feedback loop between central and retinal clocks (Hastings et al., 2003; Zele et al., 2011). For example, an individual with SAD may have decreased melanopsin sensitivity, which may only be an issue in winter when environmental light levels are lower and input is decreased. The complexity of the system is increased considering that environmental factors interact with biological factors.

\subsection{Environment}

The environmental trigger for SAD is most likely the change in the daily light/dark cycle due to a change in season or latitude (Rosenthal et al., 1984). The temporal sequence of symptom onset in SAD is most closely linked to photoperiod than other climatic variables (e.g., minutes of sunshine, global radiation, cloud cover; e.g., Young et al., 1997). In England, not only are actimetricallymeasured light levels higher in summer overall, but evening blue light is 3 times higher in summer compared to winter (Thorne et al., 2009). Research shows that individuals with SAD, however, receive the same amount of winter light compared to controls (Guillemette et al., 1998), and more in summer compared to controls (Graw et al., 1999). Therefore, individuals with SAD may be more sensitive to seasonal changes in natural light decreases in winter, or more vulnerable to this natural seasonal change (Guillemette et al., 1998).

\subsection{Summary}

Given the reliance of circadian, neuroendocrine and neurobehavioral physiology on environmental light, and the roles of these functions in SAD, we hypothesize that winter environmental light input triggers a susceptibility to low light levels. Since all individuals living at high latitudes are exposed to seasonal changes in photoperiod, predispositions must explain why only some develop SAD. Future research is needed to determine if abnormal retinal sensitivity may constitute year-round or winter-only changes in retinal sensitivity, or it may be that certain individuals are less sensitive to RHT input centrally. One possibility is that low light levels in the winter may fall below a threshold in either melanopsin-specific, or general retinal sensitivity, which is required for euthymic functioning. Such a threshold may be biologically mediated by individual differences in the circadian photoreceptor system as a whole, or melanopsin functioning specifically. Such individual differences in retinal sensitivity may have consequences for central nervous system targets involved in circadian, neuroendocrine and neurobehavioral functions, leading 
Table 2

Summary of future directions in research.

Study descriptions

Pupillometry designed to isolate the sensitivity of melanopsin cells (i.e.,

Post Illumination Pupil Response; PIPR)

Consider time of assessment, circadian phase of participant, season and/or photoperiod

Adjust for age-related changes in lens density

Review methodological considerations (Wilhelm, 2010)

Carefully chose duration, intensity (irradiance) and wavelength given specific experimental questions

Evaluate the blue-light hazard over the duration of exposure typical in light therapy for SAD

Test whether pupillometry or variations in genes involved in circadian entrainment can predict response to light therapy

Determine if long wavelengths prior to broad-spectrum light therapy can potentiate response in light therapy

Notes: See Section 3 for elaboration.

to symptoms typically seen in SAD such as sleep and eating changes as well as circadian phase shifts.

\section{Future directions}

The potential relationship between melanopsin, light, and SAD has been under-explored, in general. Table 2 details the following recommendations for areas of future research. With our recent and growing understanding of melanopsin containing ipRGCs, and the hypothesis for how melanopsin may play a role in seasonal depression, the next step is to describe a method of action for assessing the model with hypothesis testing. To date, much of the research on melanopsin physiology, especially as it might relate to seasonal variations, has been on healthy animals, and healthy humans, and very little in SAD, highlighting the need for future studies in healthy humans, those with SAD, and possibly in animal models of SAD (Workman and Nelson, 2011). Importantly, the contributions of ipRGCs to mood in humans, or animal models of depression, have not yet been described at the level of detail known for other ipRGC contributions (Schmidt et al., 2011). In testing whether or not melanopsin photoreception mediates seasonal variations in responses to light in SAD, critical issues include the nature of light stimuli, measurement of responses, and study design issues. Specifically, pupillometry designed to isolate the sensitivity of melanopsin cells from rods and cones, which has been employed in studies of retinal pathology, may lead to breakthroughs in our understanding of SAD.

\subsection{Methodological considerations}

Variables to consider in pupillometry include time of assessment, patient age, stimulus background and intensity, eye of exposure versus recording, sufficient spatial and temporal resolution in pupillometry recording equipment, and careful analysis of outcome data including appropriate handling of amplitude, blinks, and multiple observations per participant (Wilhelm, 2010). In addition, factors affecting the autonomic nervous system such as noise, arousal level, cognitive load, and medications should be controlled (Markwell et al., 2010). The effect of light stimuli on the retina can be affected by head movements, blinks, pupil constriction, and light transmission through the ocular media (Brainard et al., 1997, 2001; Gaddy et al., 1993). As the human lens ages, transmission of short wavelengths of light is reduced (Brainard et al., 1997; Lerman, 1987), so efforts to control for these age effects are necessary. Given that the sensitivity of the human visual system differs from the circadian system, it is currently more useful to quantify irradiance or photon density within a specified band of wavelengths rather than illuminance (An et al., 2009; Brainard

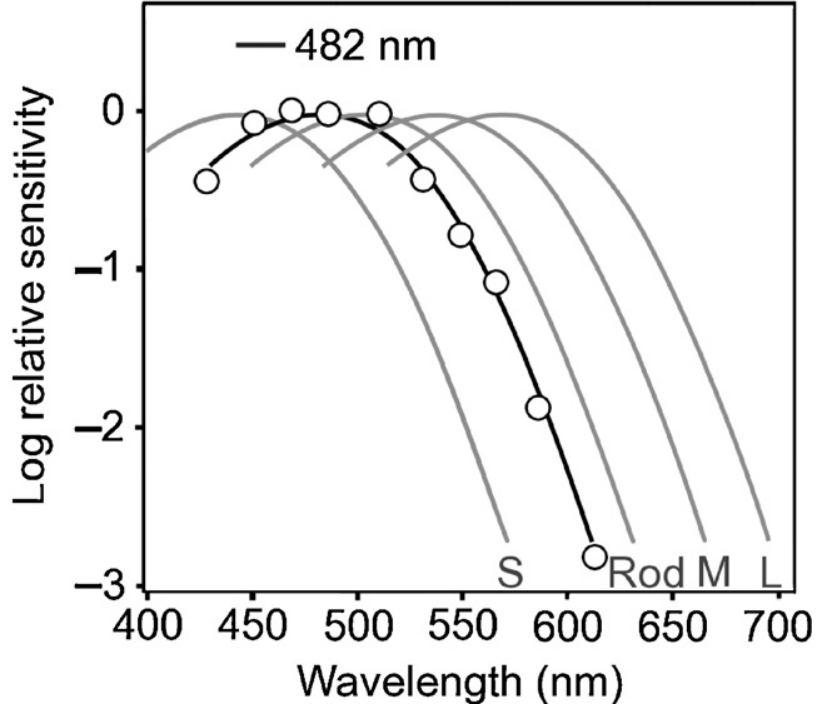

Fig. 1. Responsitivity of melanopsin compared to other photopigments. Notes: Log relative sensitivity scaled to fit an A1-based photopigment nomogram identifying $482 \mathrm{~nm}$ as the wavelength at which melanopsin-containing ganglion cells are most sensitive in the non-human primate. S - short, $\mathrm{M}$ - medium, and L- long wavelength cone cells.

Reprinted by permission from Macmillan Publishers Ltd: Nature, (Dacey et al., 2005), copyright (2005).

et al., 2001; Gooley et al., 2010). Illuminance measures reflect the wavelength sensitivity of the human visual system to light and can significantly misrepresent photic input for nonvisual responses. A number of nascent models have proposed a basis for light measurement related to circadian, neuroendocrine and neurobehavioral responses. For example, the recently described "melanopic" photometric measure of light intensity predicts melanopsin-driven pupil and circadian responses to polychromatic light in mice with only ipRGC photoreceptors (rd/rd cl mice; Enezi et al., 2011).

\subsection{Chromatic pupillometry}

Because current measures of retinal function like ERG measure electrical activity across the entire retina, the effect of relatively sparse melanopsin cells may be quite low unless stimuli are carefully designed to reflect melanopsin responses. For example, the post-illumination pupil response (PIPR) is likely to be predominately mediated by melanopsin cells as opposed to rods or cones, leading to methods designed to elicit melanopsin responses (Park et al., 2011). Studies using monochromatic light stimuli may want to approach $460 \mathrm{~nm}$ as opposed to $480 \mathrm{~nm}$ to optimally stimulate melanopsin-driven responses, as $460 \mathrm{~nm}$ is the wavelength maximally driving sustained melanopsin driven pupil responses to long duration stimuli (McDougal and Gamlin, 2010; Mure et al., 2009), as well as prolonged exposures for acute melatonin suppression (Brainard et al., 2001; Thapan et al., 2001). The spectral profile of photoreceptors (i.e., rods, cones, and ipRGCs) in the primate retina is shown in Fig. 1, demonstrating that narrow bandwidth stimuli are needed to minimize "bleed-through" of a stimulus intended to stimulate only ipRGCs. In SAD, it is more likely that sustained light input, from the environment across the day, is more etiologically significant than brief stimuli. In addition, it may be more ecologically valid to use polychromatic light stimuli when evaluating circadian, neuroendocrine and neurobehavioral responses. Finally, cones appear to provide strong early input and subsequently adapt, while melanopsin cells provide sustained input during continuous illumination without evidence for adaptation (Dollet et al., 2010; Gooley et al., 2010). In mice, rods appear to play a large role in 
circadian photoentrainment, in addition to cones, so it is important to consider rod contributions when trying to isolate the responses of ipRGCs (Altimus et al., 2010).

\subsection{Assessment timing}

Beyond careful control of stimuli parameters, the timing of light experiments is critical because of the existence of circadian variations in melanopsin cell sensitivity. As described above, melanopsin cells display a daily variation in a number of factors that may affect sensitivity (Gonzalez-Menendez et al., 2009; Hannibal et al., 2005; Sakamoto et al., 2004; Zele et al., 2011). It is not yet known if efforts to standardize timing across participants should be based on the timing of first light exposure at awakening, or based on circadian time. Each would imply different means of controling for variables known to influence melanopsin functioning including circadian time, previous light exposure, and current environmental photoperiod.

\subsection{Blue light hazard}

Concerns have been raised about the safety of both experimental and therapeutic light exposures (Gagne et al., 2011; Reme et al., 1996; Terman, 2009). Since light devices vary in their spectral composition, it is always prudent to assure light dosages given to the human eye fall within safe exposure limits. According to national and international standards, one of the defined risks of photochemical retinal injury, the blue light hazard, is highest between 400 and 500 nm (ACGIH, 2010; ANSI, 2005, ICNIRP, 1997). Researchers can use the published standards to calculate the safe limit of duration and irradiance for stimuli (Brainard et al., 2001, 2008; Glickman et al., 2006; West et al., 2011). Values for absolute irradiance and wavelength of a light source can be determined with a spectrophotometer. Measured irradiance then should be integrated using a blue-light hazard weighting function. Standards are based on exposure durations from 1 ns to $8 \mathrm{~h}$ (ACGIH, 2010; ANSI, 2005, ICNIRP, 1997). Since light therapy for SAD is typically used daily during fall and winter for 30-60 min, it is within the dosimetric range of these standards. Absolute irradiance measurements also permit experimenters to determine the photon density at each wavelength from a light source, critical for accurately interpreting the physiological, behavioral and therapeutic responses to light (Revell et al., 2010). Hence, it is important for SAD researchers to provide detail on the spectrum and irradiance of their light sources (Anderson et al., 2009; Revell et al., 2010; West et al., 2011).

\subsection{Optimizing light therapy for $S A D$}

The discovery and characterization of the melanopsin pathway triggered interest in using lights with wavelengths centered around the blue portion of the visible spectrum, or broad bandwidth light with increased intensity in the blue-appearing wavelengths. Studies have established that blue or blue-enriched lights at significantly lower light irradiances, yield similar rates of improvement in SAD as traditional bright white light therapy units (Anderson et al., 2009; Glickman et al., 2006; Meesters et al., 2011; Strong et al., 2009), and are able to phase advance rhythms (Smith et al., 2009). Outstanding questions include whether the melanopsin cells are primary in mediating light therapy's effects, and whether it may be possible to potentiate the effects of light therapy by using long wavelength light first (Gooley et al., 2010; Mure et al., 2009; Rollag, 2008). Furthermore, it is possible that gene variations could be used to predict the timing, duration, risk of side effects, and potential benefit of light therapy, opening the door to individualized treatment prescriptions in the future.

\subsection{Conclusions}

The new research on melanopsin and the circadian, neuroendocrine and neurobehavioral repsonses to light has provided an opportunity to understand the physiology behind individual differences in responses to seasonal changes in light levels. It appears that melanopsin sequence variations may increase risk for mood disorders with a seasonal pattern. Further, seasonal variations in sleep and chronotype may be mediated by different thresholds of melanopsin-based sensitivity to light. Both of these SNP-association studies, however, deserve replication. Determining if the melanopsin pathway is involved in mood and sleep disorders may help improve treatment outcomes by determining the time, duration, and wavelength for optimal light therapy. In addition, it may be possible to identify subgroups of individuals with SAD for whom melanopsin functioning may or may not be important, allowing for individually tailored treatment prescriptions.

\section{Acknowledgements}

Development of this manuscript was primarily supported by 1R03MH096119-01A1 to Kathryn A. Roecklein, Ph.D. George Brainard, Ph.D. was supported, in part, by the National Space Biomedical Research Institute through NASA NCC 9-58 and The Institute of Integrated Health. Dr. Brainard is the inventor or coinventor on three patents: USPTO Patent Serial No. 09/853,428; USPTO active continuation application No. 12657533; and pending World PCT 2005/004948AZ.

\section{References}

Altimus, C.M., Guler, A.D., Villa, K.L., McNeill, D.S., Legates, T.A., Hattar, S., 2008. Rodscones and melanopsin detect light and dark to modulate sleep independent of image formation. Proceedings of the National Academy of Sciences of the United States of America 105, 19998-20003.

Altimus, C.M., Guler, A.D., Alam, N.M., et al., 2010. Rod photoreceptors drive circadian photoentrainment across a wide range of light intensities. Nature Neuroscience 13, 1107-1112.

American Conference of Governmental Industrial Hygienists, 2010. Nonionizing radiation and fields. In: Documentation of the Threshold Limit Values and Biological Exposure Indices, Cincinnati, Ohio. American Conference of Governmenta Industrial Hygienists, pp. 135-147.

American National Standards Institute, and Illuminating Engineering Society of North America, 2005. Recommended Practice for Photobiological Safety for Lamps and Lamp Systems-General Requirements. New York. American National Standards Institute and Illuminating Engineering Society of North America, RP 27. 1-05, pp. 1-28.

An, M., Huang, J., Shimomura, Y., Katsuura, T., 2009. Time-of-day-dependent effects of monochromatic light exposure on human cognitive function. Journal of Physiological Anthropology 28, 217-223.

Anderson, J.L., Glod, C.A., Dai, J., Cao, Y., Lockley, S.W., 2009. Lux vs. wavelength in light treatment of seasonal affective disorder. Acta Physiologica Scandinavica $120,203-212$.

Aschoff, J., 1981. Biological rhythms. In: Handbook of Behavioral Neurobiology, Volume 4. Plenum Press, New York, N.Y.

Badia, P., Myers, B., Boecker, M., Culpepper, J., Harsh, J.R., 1991. Bright light effects on body temperature, alertness, EEG and behavior. Physiology \& Behavior 50, 583-588.

Berson, D.M., Castrucci, A.M., Provencio, I., 2010. Morphology and mosaics of melanopsin-expressing retinal ganglion cell types in mice. Journal of Comparative Neurology 518, 2405-2422.

Berson, D., Dunn, F., Takao, M., 2002. Phototransduction by retinal ganglion cells that set the circadian clock. Science 295, 1070-1073.

Burgess, H.J., Eastman, C.I., 2006. A late wake time phase delays the human dim light melatonin rhythm. Neuroscience Letters 395, 191-195.

Brainard, G.C., Hanifin, J.P., Greeson, J.M., Byrne, B., Glickman, G., Gerner, E., Rollag, M.D., 2001. Action spectrum for melatonin regulation in humans: evidence for a novel circadian photoreceptor. Journal of Neuroscience 21, 64056412.

Brainard, G.C., Lewy, A.J., Menaker, M., Fredrickson, R.H., Miller, L.S., Weleber, R.G., 1988. Dose-response relationship between light irradiance and the suppression of plasma melatonin in human volunteers. Brain Research 454, 212 218. 
Brainard, G.C., Rollag, M.D., Hanifin, J.P., 1997. Photic regulation of melatonin in humans: ocular and neural signal transduction. Journal of Biological Rhythms $12,537-546$.

Brainard, G.C., Sliney, D., Hanifin, J.P., Glickman, G., Byrne, B., Greeson, J.M., Jasser, S., Gerner, E., Rollag, M.D., 2008. Sensitivity of the human circadian system to short-wavelength (420-nm) light. Journal of Biological Rhythms 23, 379-386.

Cahill, G.M., Besharse, J.C., 1991. Rhythmic regulation of retinal melatonin: metabolic pathways, neurochemical mechanisms, and the ocular circadian clock. Cellular and Molecular Neurobiology 11, 529-560.

Cajochen, C., Brunner, D.P., Krauchi, K., Graw, P., Wirz-Justice, A., 2000. EEG and subjective sleepiness during extended wakefulness in seasonal affective disorder, Circadian and homeostatic influences. Biological Psychiatry 47, 610-617.

Cajochen, C., Munch, M., Kobialka, S., Krauchi, K., Steiner, R., Oelhafen, P., Orgul, S., Wirz-Justice, A., 2005. High sensitivity of human melatonin, alertness, thermoregulation, and heart rate to short wavelength light. Journal of Clinical Endocrinology and Metabolism 90, 1311-1316.

Dacey, D.M., Liao, H.W., Peterson, B.B., Robinson, F.R., Smith, V.C., Pokorny, J., 2005. Melanopsin-expressing ganglion cells in primate retina signal colour and irradiance and project to the LGN. Nature 433, 749-754.

Do, M.T., Yau, K.W., 2010. Intrinsically photosensitive retinal ganglion cells. Physiological Reviews 90, 1547-1581.

Dollet, A., Albrecht, U., Cooper, H.M., Dkhissi-Benyahya, O., 2010. Cones are required for normal temporal responses to light of phase shifts and clock gene expression. Chronobiology International 27, 768-781.

Eagles, J.M., 2004. Seasonal affective disorder: a vestigial evolutionary advantage? Medical Hypotheses 63, 767-772, Preliminary evidence for a change in spectral sensitivity of the circadian system at night.

Eastman, C.I., Gallo, L.C., Lahmeyer, H.W., Fogg, L.F., 1993. The circadian rhythm of temperature during light treatment for winter depression. Biological Psychiatry $34,210-220$

Enezi, J., Revell, V., Brown, T., Wynne, J., Schlangen, L., Lucas, R., 2011. A melanopic spectral efficiency function predicts the sensitivity of melanopsin photoreceptors to polychromatic lights. Journal of Biological Rhythms 26, 314-323.

Figueiro, M.G., Bullough, J.D., Parsons, R.H., Rea, M.S., 2005. Journal of Circadian Rhythms 3, 14.

Figueiro, M.G., Bullough, J.D., Bierman, A., Fay, C.R., Rea, M.S., 2007. On light as an alerting stimulus at night. Acta Neurobiologiae Experimentalis 67, 171-178.

French, J., Hannon, P., Brainard, G.C., 1990. Effects of bright illuminance on body temperature and human performance. Annual Review of Chronopharmacology 7, 37-40.

Gaddy, J.R., Rollag, M.D., Brainard, G.C., 1993. Pupil size regulation of threshold of light-induced melatonin suppression. Journal of Clinical Endocrinology and Metabolism 77, 1398-1401.

Gagne, A.M., Hebert, M., 2011. Atypical pattern of rod electroretinogram modulation by recent light history: a possible biomarker of seasonal affective disorder. Psychiatric Research 187, 370-374.

Gagne, A.M., Levesque, F., Gagne, P., Hebert, M., 2011. Impact of blue vs red light on retinal response of patients with seasonal affective disorder and healthy controls. Progress in Neuro-Psychopharmacology \& Biological Psychiatry 35, 227-231.

Gamlin, P.D.R., McDougal, D.H., Pokorny, J., Smith, V.C., Yau, K-W., Dacey, D.M., 2007 Human and macaque pupil responses driven by melanopsin containing retinal ganglion cells. Vision Research 47, 946-954.

Glickman, G., Byrne, B., Pineda, C., Hauck, W.W., Brainard, G.C., 2006. Light therapy for seasonal affective disorder with blue narrow-band light-emitting diodes (LEDs). Biological Psychiatry 59, 502-507.

Gooley, J.J., Lu, J., Chou, T.C., Scammell, T.E., Saper, C.B., 2001. Melanopsin in cells of origin of the retinohypothalamic tract. Nature Neuroscience 4,1165

Gooley, J.J., Lu, J., Fischer, D., Saper, C.B., 2003. A broad role for melanopsin in nonvisual photoreception. Journal of Neuroscience 23, 7093-7106.

Gooley, J.J., Rajaratnam, S.M., Brainard, G.C., Kronauer, R.E., Czeisler, C.A., Lockley, S.W., 2010. Spectral responses of the human circadian system depend on the irradiance and duration of exposure to light. Science Translational Medicine 2, 31 ra33.

Gonzalez-Menendez, I., Contreras, F., Cernuda-Cernuda, R., Garcia-Fernandez, J.M., 2009. Daily rhythm of melanopsin-expressing cells in the mouse retina. Frontiers in Cellular Neuroscience 3, 3.

Graham, D.M., Wong, K.Y., Shapiro, P., Frederick, C., Pattabiraman, K., Berson, D.M., 2008. Melanopsin ganglion cells use a membrane-associated rhabdomeric phototransduction cascade. Journal of Neurophysiology 99, 25222532.

Graw, P., Recker, S., Sand, L., Krauchi, K., Wirz-Justice, A., 1999. Winter and summer outdoor light exposure in women with and without seasonal affective disorder. Journal of Affective Disorders 56, 163-169.

Guillemette, J., Hebert, M., Paquet, J., Dumont, M., 1998. Natural bright light exposure in the summer and winter in subjects with and without complaints of seasonal mood variations. Biological Psychiatry 44, 622-628.

Hannibal, J., Fahrenkrug, J., 2004. Target areas innervated by PACAP immunoreactive retinal ganglion cells. Cell and Tissue Research 316, 99-113.

Hannibal, J., Georg, B., Hindersson, P., Fahrenkrug, J., 2005. Light and darkness regulate melanopsin in the retinal ganglion cells of the albino Wistar rat. Journal of Molecular Neuroscience 27, 147-155

Hastings, M.H., Reddy, A.B., Maywood, A.S., 2003. A clockwork web, Circadian timing in brain and periphery, in heath and disease. Nature Reviews Neuroscience 4, 649-661.
Hattar, S., Kumar, M., Park, A., Tong, P., Tung, J., Yau, K.W., Berson, D.M., 2006. Central projections of melanopsin-expressing retinal ganglion cells in the mouse. Journal of Comparative Neurology 497, 326-349.

Hattar, S., Liao, H., Takao, M., Berson, D., Yau, K., 2002. Melanopsin-containing retina ganglion cells: architecture, projections, and intrinsic photosensitivity. Science 295, 1065-1070.

Hattar, S., Lucas, R.J., Mrosovsky, N., Thompson, S., Douglas, R.H., Hankins, M.W., Lem, J., Biel, M., Hofmann, F., Foster, R.G., Yau, K.W., 2003. Melanopsin and rod-cone photoreceptive systems account for all major accessory visual functions in mice. Nature 424, 76-81.

Hebert, M., Beattie, C.W., Tam, E.M., Yatham, L.N., Lam, R.W., 2004. Electroretinography in patients with winter seasonal affective disorder. Psychiatric Research 127, 27-34.

Hebert, M., Dumont, M., Lachapelle, P., 2002. Electrophysiological evidence suggesting a seasonal modulation of retinal sensitivity in subsyndromal winter depression. Journal of Affective Disorders 68, 191-202.

International Commission on Non-Ionizing Radiation Protection, 1997. Guidelines on limits of exposure to broad-band incoherent optical radiation ( 0.38 to 3 microM). Health Physics. 73, 539-554

Kankipati, L., Girkin, C.A., Gamlin, P.D., 2010. Post-illumination pupil response in subjects without ocular disease. Investigative Ophthalmology \& Visual Science $5,2764-2769$

Kaplan, K.A., Harvey, A.G., 2009. Hypersomnia across mood disorders: a review and synthesis. Sleep Medicine Reviews 13, 275-285.

Kardon, R., Andreson, S.C., Damarjian, T.G., Grace, E.M., Stone, E., Kawasaki, A., 2011 Chromatic pupillometry in patients with retinitis pigmentosa. Ophthalmology $118,376-381$.

Kasper, S., Wehr, T.A., Bartko, J.J., Gaist, P.A., Rosenthal, N.E., 1989. Epidemiological findings of seasonal changes in mood and behavior. A telephone survey of Montgomery County, Maryland. Archives of General Psychiatry 46, 823-833.

Kawasaki, A., Kardon, R.H., 2007. Intrinsically sensitive retinal ganglion cells. Journa of Neuro-Ophthalmology 27, 195-204.

Lam, R.W., Beattie, C.W., Buchanan, A., Mador, J.A., 1992. Electroretinography in seasonal affective disorder. Psychiatry Research 43, 55-63.

Lam, R.W., Beattie, C.W., Buchanan, A., Remick, R.A., Zis, A.P., 1991. Low electrooculographic ratios in patients with seasonal affective disorder. American Journal of Psychiatry 148, 1526-1529.

Lam, R.W., Lee, S.K., Tam, E.M., Grewal, A., Yatham, L.N., 2001. An open trial of light therapy for women with seasonal affective disorder and comorbid bulimia nervosa. Journal of Clinical Psychiatry 62, 164-168

Law, R.W., Levitt, A.J. (Eds.), 1999. Canadian Consensus Guidelines for the Treatment of Seasonal Affective Disorder. Clinical and Academic Publishing, Vancouver (BC).

Lam, D.A., Miron, J.A., 1991. Temperature and the seasonality of births. Advances in Experimental Medicine and Biology 286, 73-88.

Lamont, E.W., Legault-Coutu, D., Cermakian, N., Boivin, D.B., 2007. The role of circadian clock genes in mental disorders. Dialogues in Clinical Neuroscience 9 , 333-342.

Lavoie, M.P., Lam, R.W., Bouchard, G., Sasseville, A., Charron, M.C., Gagne, A.M., Tremblay, P., Filteau, M.J., Hebert, M., 2009. Evidence of a biological effect of light therapy on the retina of patients with seasonal affective disorder. Biological Psychiatry 66, 253-258.

Lerman, S., 1987. Chemical and physical properties of the normal and aging lens, Spectroscopic (UV, florescence, phosphorescence, and NMR) analyses. American Journal of Optometry and Physiological Optics 64, 11-22.

Levitan, R.D., 2007. The chronobiology and neurobiology of winter seasonal affective disorder. Dialogues in Clinical Neuroscience 9, 315-324.

Levitan, R.D., Masellis, M., Basile, V.S., Lam, R.W., Kaplan, A.S., Davis, C., Muglia, P., Mackenzie, B., Tharmaligam, S., Kennedy, S.H., Macciardi, F., Kennedy, J.L., 2004 The dopamine-4 receptor gene associated with binge eating and weight gain in women with seasonal affective disorder: an evolutionary perspective. Biological Psychiatry 56, 665-669.

Levitan, R.D., Masellis, M., Lam, R.W., Kaplan, A.S., Davis, C., Tharmalingam, S. Mackenzie, B., Basile, V.S., Kennedy, J.L., 2006. A birth-season/DRD4 gene interaction predicts weight gain and obesity in women with seasonal affective disorder: a seasonal thrifty phenotype hypothesis. Neuropsychopharmacology $31,2498-2503$.

Lewy, A.J., 2007. Melatonin and human chronobiology. Cold Spring Harbor Symposia on Quantitative Biology 72, 623-636.

Lewy, A.J., Lefler, B.J., Emens, J.S., Bauer, V.K., 2006. The circadian basis of winter depression. Proceedings of the National Academy of Sciences of the United States of America 103, 7414-7419.

Lockley, S.W., Brainard, G.C., Czeisler, C.A., 2003. High sensitivity of the human circadian melatonin rhythm to resetting by short wavelength light. Journal of Clinical Endocrinology and Metabolism 88, 4502-4505.

Lockley, S.W., Evans, E.E., Scheer, F.A., Brainard, G.C., Czeisler, C.A., Aeschbach, D. 2006. Short-wavelength sensitivity for the direct effects of light on alertness, vigilance, and the waking electroencephalogram in humans. Sleep 29, 161-168.

Lockley, S.W., Gooley, J.J., 2006. Circadian photoreception: spotlight on the brain Current Biology 16, R795-R797.

Lu, J., Greco, M., Shiromani, P., Saper, C., 2000. Effect of lesions of the ventrolateral preoptic nucleus on NREM and REM sleep. Journal of Neuroscience 20, 3830-3842.

Lucas, R.J., Freedman, M.S., Munoz, M., Garcia-Fernandez, J.M., Foster, R.G., 1999. Regulation of the mammalian pineal by non-rod, non-cone, ocular photoreceptors. Science 284 (5413 (April 16)), 505-507. 
Lucas, R.J., Hattar, S., Takao, M., Berson, D.M., Foster, R.G., Yau, K.W., 2003. Diminished pupillary light reflex at high irradiances in melanopsin-knockout mice. Science 299, 245-247.

Lupi, D., Oster, H., Thompson, S., Foster, R.G., 2008. The acute light-induction of sleep is mediated by OPN4-based photoreception. Nature Neuroscience 11, 1068-1073.

Magnusson, A., 2000. An overview of epidemiological studies on seasonal affective disorder. Acta Psychiatrica Scandinavica 101, 176-184.

Markwell, E.L., Feigl, B., Zele, A.J., 2010. Intrinsically photosensitive melanopsin retinal ganglion cell contributions to the pupillary light reflex and circadian rhythm. Clinical and Experimental Optometry 93, 137-149.

Mathes, A., Engel, L., Holthues, H., Wolloscheck, T., Spessert, R., 2007. Daily profile in melanopsin transcripts depends on seasonal lighting conditions in the rat retina. Journal of Neuroendocrinology 19, 952-957.

McDougal, D.H., Gamlin, P.D., 2010. The influence of intrinsically-photosensitive retinal ganglion cells on the spectral sensitivity and response dynamics of the human pupillary light reflex. Vision Research 50, 72-87.

Meesters, Y., Dekker, V., Schlangen, L.J., Bos, E.H., Ruiter, M.J., 2011. Low-intensity blue-enriched white light $(750 \mathrm{~lx})$ and standard bright light $(10,000 \mathrm{~lx})$ are equally effective in treating SAD: a randomized controlled study. BMC Psychiatry $11,17$.

Miller, A., Obermeyer, W., Behan, M., Benca, R., 1998. The superior colliculus-pretectum mediates the direct effects of light on sleep. Proceedings of the National Academy of Sciences of the United States of America 95, 8957-8962.

Mure, L.S., Cornut, P.L., Rieux, C., Drouyer, E., Denis, P., Gronifier, C., Cooper, H.M., 2009. Melanopsin bistability: a fly's eye technology in the human retina. PLoS One 4, e5991.

Nelson, R.J., Denlinger, D.L., Somers, D.E. (Eds.), 2010. Photoperiodism: Biological Calendar. Oxford University Press, New York

Neumeister, A., Konstantinidis, A., Praschak-Rieder, N., Willeit, M., Hilger, E., Stastny, J., Kasper, S., 2001. Monoaminergic function in the pathogenesis of seasonal affective disorder. International Journal of Neuropsychopharmacology 4, 409-420.

Owen, J., Arendt, J., 1992. Melatonin suppression in human subjects by bright and dim light in Antarctica: time and season-dependent effects. Neuroscience Letters $137,181-184$

Ozaki, N., Rosenthal, N.E., Moul, D.E., Schwartz, P.J., Oren, D.A., 1993. Effects of phototherapy on electrooculographic ratio in winter seasonal affective disorder. Psychiatric Research 49, 99-107.

Ozaki, N., Rosenthal, N.E., Myers, F., Schwartz, P.J., Oren, D.A., 1995. Effects of season on electro-oculographic ratio in winter seasonal affective disorder. Psychiatric Research 59, 151-155.

Panda, S., Provencio, I., Tu, D.C., Pires, S.S., Rollag, M.D., Castrucci, A.M., Pletcher, M.T., Sato, T.K., Wiltshite, T., Andahazy, M., Kay, S.A., Van Gelder, R.N., Hogenesch, J.B., 2003. Melanopsin is required for non-image-forming photic responses in blind mice. Science 301, 525-527.

Park, J.C., Moura, A.L., Raza, A.S., Rhee, D.W., Kardon, R.H., Hood, D.C., 2011. Toward a clinical protocol for assessing rod cone and melanopsin contributions to the human pupil response. Investigative Ophthalmology \& Visual Science 52, 6624-6635.

Phipps-Nelson, J., Redman, J.R., Dijk, D.J., Rajaratnam, S.M., 2003. Daytime exposure to bright light, as compared to dim light, decreases sleepiness and improves psychomotor vigilance performance. Sleep 26, 695-700.

Provencio, I., Jiang, G., De Grip, W.J., Hayes, W.P., Rollag, M.D., 1998. Melanopsin, an opsin in melanophores, brain, and eye. Proceedings of the National Academy of Sciences of the United States of America 95, 340-345.

Provencio, I., Rollag, M.D., Castrucci, A.M., 2002. Photoreceptive net in the mammalian retina. This mesh of cells may explain how some blind mice can still tell day from night. Nature $415,493$.

$\mathrm{Pu}$, M., 2000. Physiological response properties of cat retinal ganglion cells projecting to suprachiasmatic nucleus. Journal of Biological Rhythms 15, 31-36.

Reme, C.E., Rol, P., Grothmann, K., Kaase, H., Terman, M., 1996. Bright light therapy in focus: lamp emission spectra and ocular safety. Technology and Health Care 4, 403-413.

Reme, C., Terman, M., Wirz-Justice, A., 1990. Are deficient retinal photoreceptor renewal mechanisms involved in the pathogenesis of winter depression? Archives of General Psychiatry 47, 878-879.

Revell, V.L., Barrett, D.C., Schlangen, L.J., Skene, D.J., 2010. Predicting human nocturnal nonvisual responses to monochromatic and polychromatic light with a melanopsin photosensitivity function. Chronobiology International 27, 1762-1777.

Roecklein, K.A., Rohan, K.J., Duncan, W.C., Rollag, M.D., Rosenthal, N.E., Lipsky, R.H., Provencio, I., 2009. A missense variant (P10L) of the melanopsin (OPN4) gene in seasonal affective disorder. Journal of Affective Disorders 114, 279-285.

Roecklein, K.A., Wong, P.M., Franzen, P.L., Hasler, B.P., Wood-Vasey, W.M., Nimgaonkar, V.L., Miller, M.A., Kepreos, K.M., Ferrell, R.E., Manuck, S.B., 2012. Melanopsin gene variations interact with season to predict sleep onset and chronotype. Chronobiology International 29, 1036-1047.

Rohan, K.J., Roecklein, K.A., Haaga, D.A.F., 2009. Biological and psychological mechanisms of seasonal affective disorder: a review and integration. Current Psychiatry Reviews 5, 37-47.

Rollag, M.D., 2008. Does melanopsin bistability have physiological consequences? Journal of Biological Rhythms 23, 396-399.
Roenneberg, T., Aschoff, J., 1990. Annual rhythm of human reproduction: I. Biology, sociology, or both? Journal of Biological Rhythms 5, 195216.

Rosen, L.N., Targum, S., Terman, M., Bryant, M., Hoffman, H., Kasper, S., 1990. Prevalence of seasonal affective disorder at four latitudes. Psychiatry Research 31 131-144.

Rosenthal, N.E., Sack, D.A., Gillin, J.C., Lewy, A.J., Goodwin, F.K., Davenport, Y., Mueller, P.S., Newsome, D.A., Wehr, T.A., 1984. Seasonal affective disorder, a description of the syndrome and preliminary findings with light therapy. Archives of Genera Psychiatry 41, 72-80.

Sakamoto, K., Liu, C., Kasamatsu, M., Pozdeyev, N., Luvone, M., Tosini, G., 2005. Dopamine regulates melanopsin mRNA expression in intrinsically photosensitive retinal ganglion cells. European Journal of Neuroscience 22, 31293136 .

Sakamoto, K., Liu, C., Tosini, G., 2004. Classical photoreceptors regulate melanopsin mRNA levels in the rat retina. Journal of Neuroscience 24, 96939697.

Schibler, U., 2007. The daily timing of gene expression and physiology in mammals Dialogues in Clinical Neuroscience 9, 257-272.

Schmidt, T.M., Chen, S-K., Hattar, S., 2011. Intrinsically photosensitive retinal ganglion cells: many subtypes, diverse functions. Trends in Neuroscience 32, 574-580.

Smith, M.R., Revell, V.L., Eastman, C.I., 2009. Phase advancing the human circadian clock with blue-enriched polychromatic light. Sleep Medicine 10, 287-294.

Strong R.E., Marchant, B.K., Reimherr, F.W., Williams, E., Soni, P., Mestas, R, 2009 Narrow-band blue-light treatment of seasonal affective disorder in adults and the influence of additional nonseasonal symptoms. Depression and Anxiety 26 273-278.

Sumova, A., Jac, M., Sladek, M., Sauman, I., Illnerova, H., 2003. Clock gene daily profiles and their phase relationship in the rat suprachiasmatic nucleus are affected by photoperiod. Journal of Biological Rhythms 18, 134-144.

Terman, M., 2009. Blue in the face. Sleep Medicine 10, 277-278.

Terman, M.A., Terman, J.S., Quitkin, F.M., McGrath, P.J., Stewart, J.W., Rafferty, B., 1989. Light therapy for seasonal affective disorder: a review of efficacy. Neuropsychopharmacology 2, 1-22.

Thapan, K., Arendt, J., Skene, D.J., 2001. An action spectrum for melatonin suppression: evidence for a novel non-rod, non-cone photoreceptor system in humans. Journal of Physiology 535, 261-267.

Thorne, H.C., Jones, K.H., Peters, S.P., Archer, S.N., Dijk, D.J., 2009. Daily and seasonal variation in the spectral composition of light exposure in humans. Chronobiology International 26, 854-866.

Tournier, B.B., Menet, J.S., Dardente, H., Poirel, V.J., Malan, A., Masson-Pevet, M. Pevet, P., Vuillez, P., 2003. Photoperiod differentially regulates clock genes expression in the suprachiasmatic nucleus of Syrian hamster. Neuroscience 118 317-322.

Travnickova, Z., Sumova, A., Peters, R., Schwartz, W.J., Illnerova, H., 1996. Photoperiod-dependent correlation between light-induced SCN c-fos expression and resetting of circadian phase. American Journal of Physiology 271 (4 Pt 2), R825-R831.

Tsai, J.W., Hannibal, J., Hagiwara, G., Colas, D., Ruppert, E., Ruby, N.F., Heller, H.C. Franken, P., Bourgin, P., 2009. Melanopsin as a sleep modulator: circadian gating of the direct effects of light on sleep and altered sleep homeostasis in Opn4(-1-) mice. PLoS Biology 7, e1000125.

Tsujimura, S., Ukai, K., Ohama, D., Nuruki, A., Yunokuchi, K., 2010. Contribution of human melanopsin retinal ganglion cells to steady-state pupil responses. Proceedings: Biological Sciences 277, 2485-2492.

Van Hook, M.J., Wong, K.Y., Berson, D.M., 2012. Dopaminergic modulation of ganglion-cell photoreceptors in rat. European Journal of Neuroscience 35, 507-518.

VanderLeest, H.T., Houben, T., Michel, S., Deboer, T., Albus, H., Vansteensel, M.J. Block, G.D., Meijer, J.H., 2007. Seasonal encoding by the circadian pacemaker of the SCN. Current Biology: CB 17, 468-473.

Wehr, T.A., 1991. The durations of human melatonin secretion and sleep respond to changes in day length (photoperiod). Journal of Clinical Endocrinology and Metabolism 73, 1276-1280.

Wehr, T.A., Duncan Jr., W.C., Sher, L., Aeschbach, D., Schwartz, P.J., Turner, E.H., Postolache, T.T., Rosenthal, N.E.,2001. A circadian signal of change of season in patients with seasonal affective disorder. Archives of General Psychiatry 58, 11081114 .

Wehr, T.A., Moul, D.E., Barbato, G., Giesen, H.A., Seidel, J.A., Barker, C., Bender, C. 1993. Conservation of photoperiod-responsive mechanisms in humans. American Journal of Physiology 265, R846-R857.

West, K.E., Jablonski, M.R., Warfield, B., Cecil, K.S., James, M., Ayers, M.A., Maida, J. Bowen, C., Sliney, D.H., Rollag, M.D., 2011. Blue light from light-emitting diodes elicits a dose-dependent suppression of melatonin in humans. Journal of Applied Physiology 110, 619-626.

Wilhelm, B.J., 2010. [The eye of the inner clock - pupil research in a new light] Klinische Monatsblätter für Augenheilkunde 227, 840-844.

Winkler, D., Pjrek, E., Praschak-Pieder, N., Lucht, M.J., Hilger, E., Konstantinidis, A. Stastny, J., Kasper, S., 2005. Actigraphy in patients with seasonal affective disorder and healthy control subjects treated with light therapy. Biological Psychiatry $58,331-336$

Witkovsky, P., 2004. Dopamine and retinal function. Documenta Ophthalmologica 108, 17-40.

Wong, K.Y., Dunn, F.A., Graham, D.M., Berson, D.M., 2007. Synaptic influences on rat ganglion-cell photoreceptors. Journal of Physiology 582, 279-296. 
Workman, J.L., Nelson, R.J., 2011. Potential animal models of seasonal affective disorder. Neuroscience \& Biobehavioral Reviews 35, 669-679.

Young, M.A., Meaden, P.M., Fogg, L.F., Cherin, E.A., Eastman, C.I., 1997. Which environmental variables are related to the onset of seasonal affective disorder? Journal of Abnormal Psychology 106, 554-562.

Zaidi, F.H., Hull, J.T., Peirson, S.N., Wulff, K., Aeschbach, D., Gooley, J.J., Brainard, G.C., Gregory-Evans, K., Rizzo 3rd, J.E., Czeisler, C.A., Foster, R.G., Moseley, M.J., Lockley, S.W., 2007. Short-wavelength light sensitivity of circadian, pupillary, and visual awareness in humans lacking an outer retina. Current Biology 17, 2122-2128.

Zele, A.J., Feigl, B., Smith, S.S., Markwell, E.R., 2011. The circadian response of intrinsically photosensitive retinal ganglion cells. PLoS One 6 e17860.

Zhang, D.Q., Belenky, M.A., Sollars, P.J., Pickard, G.E., McMahon, D.G., 2012. Melanopsin mediates retrograde visual signaling in the retina. PLoS One 7, e42647. 